\title{
Transanal minimal invasive surgery - pushing the boundaries of transanal surgery
}

\author{
Samuel O. Adegbola ${ }^{1,2}$, Kapil Sahnan ${ }^{1,2}$, Gianluca Pellino ${ }^{1,3}$, Janindra Warusavitarne ${ }^{1,2}$ \\ 'Department of Surgery, St. Mark's Hospital, Harrow, Middlesex, HA1 3UJ, UK. \\ ${ }^{2}$ Department of Surgery and Cancer, Imperial College, London, SW7 5NH, UK. \\ ${ }^{3}$ Department of Medical, Surgical, Neurological, Metabolic, and Ageing Sciences, Università della Campania "Luigi Vanvitelli", \\ Naples 80138, Italy.
}

Correspondence to: Dr. Samuel O. Adegbola, Department of Surgery, St. Mark's Hospital, Watford Road, Harrow, Middlesex, HA13UJ, UK. E-mail: samadeg@doctors.net.uk

\begin{abstract}
How to cite this article: Adegbola SO, Sahnan K, Pellino G, Warusavitarne J. Transanal minimal invasive surgery - pushing the boundaries of transanal surgery. Mini-invasive Surg 2018;2:40. http://dx.doi.org/10.20517/2574-1225.2018.55
\end{abstract}

Received: 31 Jul 2018 First Decision: 30 Oct 2018 Revised: 14 Nov 2018 Accepted: 15 Nov 2018 Published: 28 Nov 2018

Science Editor: Gordon N. Buchanan Copy Editor: Cui Yu Production Editor: Huan-Liang Wu

\begin{abstract}
Transanal minimally invasive surgery is a rapidly evolving platform surgery that is facilitating the transanal approach to colorectal surgery. Over the years since its initial description, the applications have widened and now include endoluminal and extraluminal approaches to rectal and pelvic surgery. This article discusses the various applications and future direction of research evaluating this novel technique and its role in colorectal practice.
\end{abstract}

Keywords: Transanal minimal invasive surgery, rectal surgery

\section{INTRODUCTION}

Transanal minimally invasive surgery (TAMIS) describes a platform that evolved from transanal techniques to address mid to low rectal lesions. It represents an alternative to conventional transanal excision of rectal lesions, transanal endoscopic microsurgery (TEM)/transanal endoscopic operation (TEO) and endoscopic submucosal dissection in selected rectal lesions. TAMIS was introduced in 2009 by Atallah et al. ${ }^{[1]}$ for the purpose of performing endoluminal rectal surgery, and its use has since expanded to include extraluminal approaches, most prominent of which is the transanal total mesorectal excision (taTME) for rectal cancers. Instead of a purpose-designed proctoscope as is the case with TEM, TAMIS is characterised by the use of a single-site port transanally in combination with ordinary laparoscopic instruments, a laparoscopic camera lens, and a standard laparoscopic carbon dioxide insufflator. It was developed out of the need for a practical alternative to TEM that was both affordable and technically feasible without special-

Cc (i) (c) The Author(s) 2018. Open Access This article is licensed under a Creative Commons Attribution 4.0 International License (https://creativecommons.org/licenses/by/4.0/), which permits unrestricted use, sharing, adaptation, distribution and reproduction in any medium or format, for any purpose, even commercially, as long as you give appropriate credit to the original author(s) and the source, provide a link to the Creative Commons license, and indicate if changes were made. 
ized equipment ${ }^{[2]}$. The benefit over TEM was mostly in overcoming the steep learning curve and associated expense. Other reported benefits favouring TAMIS include rapid set-up time, 360 degrees vs. 220 degrees of visibility within the rectal lumen, the adaptability to available laparoscopic instruments, and the ease of patient and equipment positioning within the operating theatre ${ }^{[2-4]}$. Furthermore, it is hypothesised that the soft transanal access platform with TAMIS offers less sphincter traction, although this has not been conclusively demonstrated to translate to better functional outcome postoperatively ${ }^{[4]}$.

The evolution of TAMIS has seen a rapid progression into a technique that is now an established practice of some colorectal surgeons globally and has seen some of the cutting-edge developments in surgical innovation in colorectal surgery ${ }^{[5,6]}$. Since the inception of TAMIS, several changes have been made to optimize the technique and broaden indications, reflecting the stages described by the IDEAL ("Idea, Development, Exploration, Assessment, Long-term study") framework for surgical innovation ${ }^{[7-9]}$. The ease of access to the rectum and pelvis that is provided by TAMIS allows it to be used for various additional applications. In this article, we discuss the widening applications and latest developments in TAMIS use, which signpost the future direction with this new platform.

\section{EARLY APPLICATION}

\section{Local excision of rectal neoplasia}

Initially TAMIS was used largely for local excision of rectal lesions within the context of benign (e.g., adenomatous polyps unsuitable for endoscopic resection) or early-stage (T1) malignant tumours with a low risk for lymphatic involvement at the time of operation or local excision as a form of palliation in patients (T3 and above) who are medically unfit or unwilling to go ahead with standard oncologic surgery ${ }^{[10-13]}$. Studies report similar advantages conferred with TAMIS as for TEM when compared with conventional transanal resection, with more intact, non-fragmented specimens, negative resection margins and lower recurrence rates ${ }^{[6,12]}$. For very distal lesions or those at or just above the dentate line, a hybrid approach with standard transanal and TAMIS equipment can facilitate resection ${ }^{[12,14]}$. TAMIS has also been considered in local excision of tumour site in patients with locally advanced rectal cancer following neoadjuvant therapy; for the purpose of confirming mural complete pathologic response ${ }^{[15]}$. This approach is considered acceptable in certain scenarios in view of the low risk of occult node positivity for ypTo lesions is low, at $3 \%-6 \%{ }^{[12,16-19]}$. There is limited data evaluating the effectiveness of TAMIS for resection of neuroendocrine (e.g., carcinoid tumours) however, small series suggest it is feasible for excision of small primary rectal carcinoids, or following incomplete endoscopic removal ${ }^{[15,20]}$. A systematic review in $2014^{[10]}$ reported on a combined 390 TAMIS procedures for local excision of rectal neoplasia with publications from 16 countries. They reported an average excised lesion size of $3.1 \mathrm{~cm}$ (range $0.8-4.75 \mathrm{~cm}$ ) with an average distance of $7.6 \mathrm{~cm}$ from the anal verge (range 3-15 cm). Of the 390 TAMIS procedures included, 152 lesions were benign (adenomas and high-grade dysplasias) 209 were malignant (carcinomas in situ/adenocarcinomas), $23(0.05 \%)$ were for neuroendocrine lesions (e.g., carcinoid), three were for fibrosis (e.g., benign scar), one mucocele, one gastrointestinal stromal tumour, and one melanoma ${ }^{[10]}$. Within the series there were 29/390 complications (7.4\%), the most common of which was self-limiting bleeding (10/29). Only five cases (1.28\%) were graded on the Clavien Dindo classification as grade 3 (one case of bleeding requiring reintervention and four cases of inadvertent peritoneal entry) and no complications were graded higher. The conversion rate was $2.31 \%(n=9)$ necessitating either a transanal excision with a Park's retractor, TEM surgery or laparoscopy. The recurrence rate was low at $2.7 \%$ (7/259), albeit with only short term follow-up, with mean duration of follow-up of approximately seven months. The concept of local excision for rectal cancer is of course a hotly debated topic with both strong proponents and opponents. The role of radiotherapy followed by local excision for early rectal cancers is an emerging field and has the potential for a complete re-evaluation of current standards in rectal cancer surgery with a larger emphasis on organ preservation. A phase-II study enrolled 63 patients with T3 or low-lying T2 rectal cancer who received local excision after achieving complete response to neoadjuvant chemoradiation ${ }^{[21]}$. They found excellent cumulative 3-year overall 
survival (91.5\%), disease-free survival (91\%) and local disease-free survival (97\%) in the 43 patients who fulfilled the criteria for watchful surveillance after local excision ${ }^{[21]}$. A different study compared the functional outcomes and quality of life of local excision $v s$. total mesorectal excision after chemoradiation, and found that local excision achieved better results in both ${ }^{[22]}$. The paucity of data will probably benefit from prospective studies which have been set to assess the role of organ preserving strategies in a selected category of rectal cancer patients, and TAMIS would probably be the ideal surgical approach ${ }^{[2,24]}$. One other innovative indication for the TAMIS platform is the recently described transanal endoscopic submucosal resection which is a hybrid procedure combining the skills of the endoscopist and the laparoscopic surgeon to remove large and complex rectal lesions (up to $18 \mathrm{~cm}$ in length). Preliminary results on 17 patients from a tertiary referral centre, with complex lesions $(>5 \mathrm{~cm}$ lesions, recurrent polyps with submucosal fibrosis) demonstrated the feasibility of the technique ${ }^{[25]}$. Pioneers of the procedure reported $91 \%$ complete endoscopic excision in a single session, sometimes requiring the combination of more than one endoscopic technique $(27 \% \text { of cases })^{[26]}$. Intraoperative bleeding $(72.7 \%)$ was successfully controlled with clips and coagulation; suturing was performed in $9 \%$. Of those who completed the 3-6 months follow-up none developed recurrences, whereas one patient was referred to surgery for a malignant polyp. Such innovations push the boundaries of minimally invasive surgery as previously patients with large/complex lesions would have required an anterior resection.

\section{WIDER APPLICATIONS OF THE TAMIS PLATFORM AND FUTURE DIRECTION}

The TAMIS platform has seen rapid evolution, and the breath of applications continues to increase ${ }^{[12]}$. Some of these will be discussed below.

\section{Transanal total mesorectal excision approach to rectal cancer excision}

The spectrum of pathology that can be managed with TAMIS has broadened from excision of intraluminal small rectal lesions to a full total mesorectal excision (TME) ${ }^{[14,27]}$. In 2015, Lacy et al ${ }^{[28]}$ reported on their experience in 140 cases, using a hybrid approach of transabdominal-taTME and several other series have followed. The TaTME International registry is a prospective, secure online database where surgeons can upload data of TAMIS proctectomy performed on a voluntary basis (https://tatme.medicaldata.eu/). TaTME has been associated with poor pathological outcomes in less than $7.5 \%$ of patients, who - of note received surgery during the first years of technique development ${ }^{[2]}$. The latest analysis available of patients from the registry included data on 1540 rectal cancers, and confirmed the feasibility and safety of this technique highlighting the key points for optimal short-term outcomes ${ }^{[30]}$. The keenly anticipated COLOR III trial ${ }^{[31]}$ aims to compare laparoscopic with taTME and should help address questions on the quality of surgery in particular the oncological outcomes in the treatment of mid-low rectal cancers.

\section{TAMIS for benign rectum excision}

In 2012, Wolthuis et al. ${ }^{[32]}$ described a case report of transanal single port access to facilitate distal rectal mobilization with hand-sewn coloanal anastomosis for a patient with refractory pelvic inflammation secondary to cryptoglandular fistula. In so doing, they proposed the further development of hybrid procedures in paving the way to full transanal resection. TAMIS has since been used in hybrid technique with transabdominal laparoscopic surgery/single incision laparoscopic surgery (SILS) for rectal excision in the context of inflammatory bowel disease. This includes proctectomy in Crohn's disease and also for restorative proctocolectomy (RPC) or completion proctectomy and ileal pouch-anal anastomosis [i.e., transanal ileal pouch anal anastomosis (IPAA) or ta-IPAA] in ulcerative colitis (UC) ${ }^{[33-36]}$. Ta-IPAA is done either as a 2-stage (total proctocolectomy and IPAA/closure of ileostomy) or 3-stage procedure, i.e., with (subtotal colectomy/proctectomy and IPAA/closure of ileostomy $)^{[34]}$. Ta-IPAA is often performed with close rectal dissection and single stapled anastomosis. Early reports suggest the TAMIS platform is a feasible and safe alternative to conventional laparoscopic RPC performed for UC. Advantages suggested include the facilitated pelvic dissection, avoidance of repeated application of staplers and when combined with SILS ap- 
proach results in fewer scars with improved cosmetic results ${ }^{[34]}$. In 2017, a retrospective comparative study assessing ta-IPAA ( $n=97$ patients) vs. transabdominal minimally invasive (completion) proctectomy with IPAA (119 patients) assessed 90-day morbidity between the two groups ${ }^{[37]}$. They demonstrated safety of the ta-IPAA approach in patients with UC, with decreasing rates of postoperative morbidity, lower conversion rate and shorter postoperative length of stay ${ }^{[37]}$. An analysis of the benign cases extracted from the TaTME International registry reported leak rates of less than $5 \%$ in the first 69 Ta-IPAA patients included, with $23 \%$ overall complication rates (most of them grade I-II Clavien-Dindo ${ }^{[38]}$. Similarly, analyses of the entire cohort of patients with inflammatory bowel disease who underwent TAMIS proctectomy with or without restoration of the continuity confirmed the safety of the technique ${ }^{[39]}$. Four percent experienced ClavienDindo III complications; surgery was, however, technically more demanding in Crohn's disease with inability to proceed with TAMIS in $20 \%$ of patients and more frequent wound complications ${ }^{[39]}$.

The techniques employed offer an added advantage as a form of natural orifice transanal endoscopic surgery with laparoscopic/SILS assistance and is potentially a well suited technique for inflammatory bowel disease ${ }^{[33,36,40,41]}$. Recent European guidelines on surgery in $U C^{[42]}$ acknowledge these new variants of natural orifice surgery (i.e., TAMIS for proctectomy with or without an anastomosis). However, in view of their an early development stage, it is noted that future prospective (and comparative) studies would be required to assess benefit in terms of functional outcomes and their role in management of patients with $\mathrm{UC}^{[42]}$.

\section{Redo pelvic surgery}

In 2016 Borstlap et al. ${ }^{[43]}$ shared their experience of TAMIS in redo pelvic surgery addressing complications or necessity for surgery following rectal resections and primary anastomosis and also in the context of pouch surgery. In a series of 17 patients, they described TAMIS use for redo anastomotic surgery in 13 and pouch problems in the remaining four. A majority of patients had chronic presacral sinus due to prior anastomotic dehiscence after low anterior resection, and pouch problems were due to efferent loop syndrome, obstructive pouch polyp, voiding disorder, recurrent cuffitis. Using a hybrid technique of transanal/ transabdominal approach for most (15/17), feasibility was defined as the ability to complete rendezvous from transanal to transabdominal level (at seminal vesicles/anterior curvature of neorectum in women) beyond the anastomosis ${ }^{[43]}$. Whereas for those with sole TAMIS procedures $(2 / 17)$ feasibility was defined as the ability to perform safer dissection with better visualisation of the dehisced anastomosis. This increased visibility is proposed to be one of the likely benefits of the TAMIS approach in redo pelvic surgery, with supposed lower risk of neurovascular injury, however this remains yet to be proven ${ }^{[43]}$. The authors proposed the merits of TAMIS in the context of redo surgery of the above nature to be judged on feasibility and complication rate, in view of the absence of oncological issues. Another potential anastomotic problem that can be addressed by this platform is the treatment of completely occluded anastomotic strictures, with incision of the blind end with electrocautery following confirmation of proximal lumen with contrast ${ }^{[44]}$.

\section{Pelvic exenterative surgery}

The TAMIS platform has been applied to exenterative surgery in the context of advanced rectal cancer, with case reports by two groups of authors, both from $\operatorname{Japan}^{[45-47]}$. The technique described involves a hybrid transabdominal/transanal approach with the use of TAMIS access port following incision of the perianal skin incision and subsequent perirectal tissue and muscles dissection until the abdominal cavity is encountered $^{[45]}$. The platform is proposed to facilitate the pelvic dissection with removal of the pelvic organs within the visceral pelvic fascia ${ }^{[46]}$. Clearly, evidence is very limited at this stage, however, there may well be future adoption of this technique in view of the proposed advantages of increased visibility, reduced blood loss and smaller perineal wounds with the TAMIS approach ${ }^{[46]}$. As the series are small and assessing feasibility there is no formal comparison available with the conventional open technique, and the oncological outcomes and long term safety of this technique will need to be evaluated in future studies. 


\section{ROBOTIC TAMIS}

Robotic transanal surgery is one of the developments which have arisen from the natural evolution of TAMIS. It was initially described in a cadaveric model by Atallah and colleagues ${ }^{[48]}$ and was proposed at the time as a potential tool to counteract some of the limitations of using standard laparoscopic instruments and approaches via a TAMIS platform. In particular, limitation of operative navigation in the confined rectal lumen, and the resultant restriction in instrument working angles $v s$. camera angle can make transanal surgery challenging. Proposed advantages of combining robotic technique with the TAMIS platform include greater precision for dissection and ease of intraluminal suturing of the surgical defect compared to standard TAMIS ${ }^{[5]}$. Atallah et al ${ }^{[49]}$ subsequently demonstrated the option of using the da Vinci surgical robot to perform TAMIS as an option for local excision of rectal lesions, later going on to perform a pilot study for transanal TME using the robotic-TAMIS platform ${ }^{[49]}$. The feasibility and safety of these approaches have been confirmed in other cohort series from various groups in Europe and America, demonstrating its feasibility and safety in both local excision and taTME ${ }^{[7,49-54]}$. The pioneers of this technique also describe its use in the repair of complex fistula, specifically in the repair of three rectourethral fistulae and 1 anastomotic fistula, using the robotic TAMIS platform for suture closure of the fistula and flap construction of the rectal wall ${ }^{[53]}$. The robotic TAMIS use is still very much in its infancy, and studies are currently experimental, demonstrate feasibility with anecdotal reports of advantages in ergonomics, tremor elimination, motion scaling and instruments with multiple degrees of freedom ${ }^{[55]}$. However, the financial implications as well as the increased set up time of robotic techniques may well serve as a significant counteraction to widespread use. As this modality evolves with technology, further studies will be required to determine whether it offers significant patient benefit.

\section{DISCUSSION}

There has been a rapid explosion in the TAMIS platform, with widening use for intraluminal and extraluminal pelvic surgery. The reported ease of access to the rectum and pelvis lends use to various additional applications as described. Furthermore, the rapid development of compatible instruments, ports, and equipment is allowing further refinement to improve the technical approach to this complex area of colorectal surgery. The cost savings, potentially shorter learning curve for trained colorectal surgeons and increased incorporation into surgical training in comparison to $\mathrm{TEM}^{[56]}$, are likely to stimulate an increase in procedures being performed using the TAMIS modality. Comparative studies will however be required to address benefit between these two techniques as none currently exist.

Martin-Perez et al. ${ }^{[10]}$ described TEM surgery (equipment by Richard Wolf GMBH, Knittlingen, Germany) as being born out of the need to improve on conventional transanal excision with a Park's retractor. TEM was soon followed with reports of TEO (equipment by Karl Storz GmbH, Tutlingen, Germany), which similarly uses a rigid rectoscope, but employs a 2-D high definition camera compared with TEM's 3-D and thus obviating the need for specially designed instrumentation and equipment as is required with TEM. When compared with TEM, TEO has been reported to offer similar results in terms of quality of surgical resections and surgical difficulty, however, there is limited published evidence on its use ${ }^{[57-60]}$. TAMIS was born out the need to make transanal surgery more accessible to all, cost-effective and with a more translatable learning-curve. The spectrum of pathology that can be managed with TAMIS has already broadened from excision of intraluminal small rectal lesions to a full $\mathrm{TME}^{[43]}$. Short-term outcomes for TaTME show shorter operative times, lower readmission rates, and acceptable morbidity and mortality with satisfactory oncological resection quality ${ }^{[5,28,61]}$. As with most pathology a nuanced approach is necessitated and TAMIS offers that for low lying rectal lesions and has particular benefit in complex cases such as in obese male patients. Here TAMIS offers visibility and technical advantage for a presumed narrow pelvis and is advantageous where exposure to the distal rectum from the abdominal approach can be challenging ${ }^{[5]}$. The improved transanal visibility and exposure as well as proposed technical advantage has led to a breadth of 
applications, with increasing use in benign pathologies including repair of recto-urethral fistula, ligation of distal rectal haemorrhage, resection of tail-gut/duplication cysts, removal of rectal foreign body ${ }^{[62,63]}$. Where uncertainty or complexity exists pre-operative planning and rehearsal with imaging adjuncts has been shown to be beneficial and can aid guide surgery in complex cases ${ }^{[64]}$. The utility of novel imaging techniques (e.g., 3D imaging, stereotactic surgery) in preoperative surgical planning and intraoperative mapping has been recently showed both in benign conditions and cancer ${ }^{[65-69]}$. This might allow a truly personalized approach with TAMIS proctectomy, where the extent of the TME can be adapted to disease features and patient needs.

Long-term oncologic outcomes and controlled trials of the technique are needed to guide further use in clinical practice. As the interest and uptake of this exciting new platform continues to rise exponentially ${ }^{[70]}$, further prospective and comparative studies will be beneficial in evaluating this platform and shaping its role. Together with following international guidelines and recommendations, surgeons willing to offer their patients the option for TAMIS need to follow the training pathways and accreditation which have been set for the safe implementation of the technique into clinical practice. Under this light, a critical role is also played by honest participation into International registries, which can capture a wider, real-life perspective about performance, safety and patient-relevant outcomes of surgical procedures. Consensus exercises will also be useful in defining patient selection criteria and indications for its use in the armamentarium of colorectal surgery.

\section{DECLARATIONS}

\section{Authors' contributions}

Conceptualised the topic and oversaw direction of narrative: Warusavitarne J

Drafted the manuscript: Adegbola SO

Performed literature review, prepared the manuscript: Adegbola SO, Sahnan K, Pellino G

Revised the manuscript critically, prepared the final version: all authors

\section{Availability of Data and Materials}

Not applicable.

\section{Financial support and sponsorship}

Kapil Sahnan is supported by a Royal College of Surgeons of England Research Scholarship. The other authors have no conflict of interests or financial ties to disclose.

\section{Conflicts of interest}

All authors declared that there are no conflicts of interest.

\section{Ethical approval and consent to participate}

Not applicable.

\section{Consent for publication}

Not applicable.

\section{Copyright}

CThe Author(s) 2018.

\section{REFERENCES}

1. Atallah S, Albert M, Larach S. Transanal minimally invasive surgery: a giant leap forward. Surg Endosc 2010;24:2200-5.

2. deBeche-Adams T, Nassif G. Transanal minimally invasive surgery. Clin Colon Rectal Surg 2015;28:176-80.

3. Young DO, Kumar AS. Local excision of rectal cancer. Surg Clin North Am 2017;97:573-85. 
4. Quaresima S, Balla A, Franceschilli L, La Torre M, Iafrate C, et al. Transanal minimally invasive surgery for rectal lesions. JSLS 2016; doi: 10.4293/JSLS.2016.00032.

5. Keller DS, Haas EM. Transanal minimally invasive surgery: state of the art. J Gastrointest Surg 2016;20:463-9.

6. Plummer JM, Leake PA, Albert MR. Recent advances in the management of rectal cancer: no surgery, minimal surgery or minimally invasive surgery. World J Gastrointest Surg 2017;9:139-48.

7. Hompes R, Rauh SM, Ris F, Tuynman JB, Mortensen NJ. Robotic transanal minimally invasive surgery for local excision of rectal neoplasms. Br J Surg 2014;101:578-81.

8. Hirst A, Philippou Y, Blazeby J, Campbell B, Campbell M, et al. No surgical innovation without evaluation: evolution and further development of the IDEAL framework and recommendations. Ann Surg 2018; doi: 10.1097/SLA.0000000000002794.

9. McCulloch P, Altman DG, Campbell WB, Flum DR, Glasziou P, et al. No surgical innovation without evaluation: the IDEAL recommendations. Lancet 2009;374:1105-12.

10. Martin-Perez B, Andrade-Ribeiro GD, Hunter L, Atallah S. A systematic review of transanal minimally invasive surgery (TAMIS) from 2010 to 2013. Tech Coloproctol 2014;18:775-88.

11. Yoshitomi M, Hasegawa S, Takahashi R, Hida K, Kawada K, et al. Transanal minimally invasive surgery for local excision of early rectal tumor. Asian J Endosc Surg 2018;11:182-4.

12. deBeche-Adams T, Hassan I, Haggerty S, Stefanidis D. Transanal minimally invasive surgery (TAMIS): a clinical spotlight review. Surg Endosc 2017;31:3791-800.

13. Giannoulopoulos D, Nastos C, Gavriatopoulou M, Vezakis A, Dellaportas D, et al. The role of TAMIS (transanal minimally invasive surgery) in the management of advanced rectal cancer - one shared story of three exceptional cases. J Invest Surg 2018; doi: $10.1080 / 08941939.2017 .1418462$

14. Keller DS, Tahilramani RN, Flores-Gonzalez JR, Mahmood A, Haas EM. Transanal minimally invasive surgery: review of indications and outcomes from 75 consecutive patients. J Am Coll Surg 2016;222:814-22.

15. Lim SB, Seo SI, Lee JL, Kwak JY, Jang TY, et al. Feasibility of transanal minimally invasive surgery for mid-rectal lesions. Surg Endosc 2012;26:3127-32.

16. Lu JY, Lin GL, Qiu HZ, Xiao Y, Wu B, et al. Comparison of transanal endoscopic microsurgery and total mesorectal excision in the treatment of T1 rectal cancer: a meta-analysis. PLoS One 2015;10:e141427.

17. Kundel Y, Brenner R, Purim O, Peled N, Idelevich E, et al. Is local excision after complete pathological response to neoadjuvant chemoradiation for rectal cancer an acceptable treatment option? Dis Colon Rectum 2010;53:1624-31.

18. Kim CJ, Yeatman TJ, Coppola D, Trotti A, Williams B, et al. Local excision of T2 and T3 rectal cancers after downstaging chemoradiation. Ann Surg 2001;234:352-8.

19. Yeo SG, Kim DY, Kim TH, Chang HJ, Oh JH, et al. Pathologic complete response of primary tumor following preoperative chemoradiotherapy for locally advanced rectal cancer: long-term outcomes and prognostic significance of pathologic nodal status (KROG 0901). Ann Surg 2010;252:998-1004.

20. Lee TG, Lee SJ. Transanal single-port microsurgery for rectal tumors: minimal invasive surgery under spinal anesthesia. Surg Endosc 2014;28:271-80

21. Pucciarelli S, De Paoli A, Guerrieri M, La Torre G, Maretto I, et al. Local excision after preoperative chemoradiotherapy for rectal cancer: results of a multicenter phase II clinical trial. Dis Colon Rectum 2013;56:1349-56.

22. Pucciarelli S, Giandomenico F, De Paoli A, Gavaruzzi T, Lotto L, et al. Bowel function and quality of life after local excision or total mesorectal excision following chemoradiotherapy for rectal cancer. Br J Surg 2017;104:138-47.

23. Barina A, De Paoli A, Delrio P, Guerrieri M, Muratore A, et al. Rectal sparing approach after preoperative radio- and/or chemotherapy (RESARCH) in patients with rectal cancer: a multicentre observational study. Tech Coloproctol 2017;21:633-40.

24. Rombouts AJM, Al-Najami I, Abbott NL, Appelt A, Baatrup G, et al. Can we save the rectum by watchful waiting or TransAnal microsurgery following (chemo) radiotherapy versus total mesorectal excision for early rectal cancer (STAR-TREC study)?: protocol for a multicentre, randomised feasibility study. BMJ Open 2017;7:e019474.

25. Tsiamoulos ZP, Warusavitarne J, Faiz O, Castello-Cortes A, Elliott T, et al. A new instrumental platform for trans-anal submucosal endoscopic resection (TASER). Gut 2015;64:1844-6.

26. Tsiamoulos ZP, Warusavitarne J, Elliott T, Saunders BP. OC-048 trans-anal submucosal endoscopic resection (taser): a new endo-surgical approach to the resection of giant rectal lesions. Gut 2014;63:A23-4.

27. Fernández-Hevia M, Delgado S, Castells A, Tasende M, Momblan D, et al. Transanal total mesorectal excision in rectal cancer: shortterm outcomes in comparison with laparoscopic surgery. Ann Surg 2015;261:22-7.

28. Lacy AM, Tasende MM, Delgado S, Fernandez-Hevia M, Jimenez M, et al. Transanal total mesorectal excision for rectal cancer: outcomes after 140 patients. J Am Coll Surg 2015;221:415-23.

29. Penna M, Hompes R, Arnold S, Wynn G, Austin R, et al. Transanal total mesorectal excision: International registry results of the first 720 cases. Ann Surg 2017;266:111-7.

30. Penna M, Hompes R, Arnold S, Wynn G, Austin R, et al. Incidence and risk factors for anastomotic failure in 1594 patients treated by transanal total mesorectal excision: results from the international TaTME registry. Ann Surg 2018; doi: 10.1097/ SLA.0000000000002653.

31. Deijen CL, Velthuis S, Tsai A, Mavroveli S, de Lange-de Klerk ES, et al. COLOR III: a multicentre randomised clinical trial comparing transanal TME versus laparoscopic TME for mid and low rectal cancer. Surg Endosc 2016;30:3210-5.

32. Wolthuis AM, Cini C, Penninckx F, D'Hoore A. Transanal single port access to facilitate distal rectal mobilization in laparoscopic rectal sleeve resection with hand-sewn coloanal anastomosis. Tech Coloproctol 2012;16:161-5.

33. Wolthuis AM, de Buck van Overstraeten A, D’Hoore A. Dynamic article: transanal rectal excision: a pilot study. Dis Colon Rectum 2014;57:105-9. 
34. Leo CA, Samaranayake S, Perry-Woodford ZL, Vitone L, Faiz O, et al. Initial experience of restorative proctocolectomy for ulcerative colitis by transanal total mesorectal rectal excision and single-incision abdominal laparoscopic surgery. Colorectal Dis 2016;18:1162-6.

35. de Buck van Overstraeten A, Wolthuis AM, D'Hoore A Transanal completion proctectomy after total colectomy and ileal pouch-anal anastomosis for ulcerative colitis: a modified single stapled technique. Colorectal Dis 2016;18:0141-4.

36. Tasende MM, Delgado S, Jimenez M, Del Gobbo GD, Fernández-Hevia M, et al. Minimal invasive surgery: NOSE and NOTES in ulcerative colitis. Surg Endosc 2015;29:3313-8.

37. de Buck van Overstraeten A, Mark-Christensen A, Wasmann KA, Bastiaenen VP, Buskens CJ, et al. Transanal versus transabdominal minimally invasive (completion) proctectomy with ileal pouch-anal anastomosis in ulcerative colitis: a comparative study. Ann Surg 2017;266:878-83.

38. Pellino G, Sahnan K, Penna M, Adegbola S, Chandrasinghe P, et al. OP017 Transanal minimally invasive proctectomy with ileal pouch anal anastomosis (Ta-IPAA) in patients with ulcerative colitis: a cohort study from the TaTME international database. J Crohns Colitis 2018;12:S012-3.

39. Pellino G, Sahnan K, Penna M, Adegbola S, Chandrasinghe P, et al. P482 Transanal minimally invasive proctectomy (TaMIP) in patients with inflammatory bowel diseases (IBD) within the TaTME international database. J Crohns Colitis 2018;12:S348.

40. Sylla P, Bordeianou LG, Berger D, Han KS, Lauwers GY, et al. A pilot study of natural orifice transanal endoscopic total mesorectal excision with laparoscopic assistance for rectal cancer. Surg Endosc 2013;27:3396-405.

41. Warusavitarne J, Kotze PG. Double single-port transanal pouch surgery: a novel technique for rectal excision and ileo-anal pouch anastomosis for ulcerative colitis. J Coloproctology 2017;37:328-31.

42. Øresland T, Bemelman WA, Sampietro GM, Spinelli A, Windsor A, et al. European evidence based consensus on surgery for ulcerative colitis. J Crohns Colitis 2015;9:4-25.

43. Borstlap WA, Harran N, Tanis PJ, Bemelman WA. Feasibility of the TAMIS technique for redo pelvic surgery. Surg Endosc 2016;30:5364-71.

44. Bong JW, Lim SB. Transanal minimally invasive surgery as a treatment option for a completely occluded anastomosis after low anterior resection: a new approach to severe anastomotic stenosis. Asian J Endosc Surg 2018; doi: 10.1111/ases.12599.

45. Hayashi K, Kotake M, Kakiuchi D, Yamada S, Hada M, et al. Laparoscopic total pelvic exenteration using transanal minimal invasive surgery technique with en bloc bilateral lymph node dissection for advanced rectal cancer. Surg Case Rep 2016;2:74.

46. Uematsu D, Akiyama G, Sugihara T, Magishi A, Ono K, et al. Transanal total pelvic exenteration with sphincter-preserving surgery. Dis Colon Rectum 2018;61:641.

47. Uematsu D, Akiyama G, Sugihara T, Magishi A, Yamaguchi T, et al. Transanal total pelvic exenteration: pushing the limits of transanal total mesorectal excision with transanal pelvic exenteration. Dis Colon Rectum 2017;60:647-8.

48. Atallah S, Nassif G, Polavarapu H, deBeche-Adams T, Ouyang J, et al. Robotic-assisted transanal surgery for total mesorectal excision (RATS-TME): a description of a novel surgical approach with video demonstration. Tech Coloproctol 2013;17:441-7.

49. Atallah S, Martin-Perez B, Pinan J, Quinteros F, Schoonyoung H, et al. Robotic transanal total mesorectal excision: a pilot study. Tech Coloproctol 2014;18:1047-53.

50. Verheijen PM, Consten EC, Broeders IA. Robotic transanal total mesorectal excision for rectal cancer: experience with a first case. Int J Med Robot 2014;10:423-6.

51. Gómez Ruiz M, Palazuelos CM, Martín Parra JI, Alonso Martín J, Cagigas Fernández C, et al. Nueva técnica de proctectomía trasanal con escisión total del mesorrecto totalmente robótica en el tratamiento del cáncer de recto. Cirugía Española 2014;92:356-61.

52. Vallribera Valls F, Espín Bassany E, Jiménez-Gómez LM, Ribera Chavarría J, Armengol Carrasco M. Robotic transanal endoscopic microsurgery in benign rectal tumour. J Robot Surg 2014;8:277-80.

53. Atallah S, Martin-Perez B, Parra-Davila E, deBeche-Adams T, Nassif G, et al. Robotic transanal surgery for local excision of rectal neoplasia, transanal total mesorectal excision, and repair of complex fistulae: clinical experience with the first 18 cases at a single institution. Tech Coloproctol 2015;19:401-10.

54. Erenler I, Aytac E, Bilgin IA, Baca B, Hamzaoglu I, et al. Robotic transanal minimally invasive surgery (R-TAMIS) with the da Vinci Xi System - a video vignette. Colorectal Dis 2017;19:401.

55. Hompes R. Robotics and transanal minimal invasive surgery (TAMIS): the "sweet spot" for robotics in colorectal surgery? Tech Coloproctol 2015;19:377-8.

56. Thompson EV, Bleier JI. Transanal minimally invasive surgery. Clin Colon Rectal Surg 2017;30:112-9.

57. Nieuwenhuis DH, Draaisma WA, Verberne GH, van Overbeeke AJ, Consten EC. Transanal endoscopic operation for rectal lesions using two-dimensional visualization and standard endoscopic instruments: a prospective cohort study and comparison with the literature. Surg Endosc 2009;23:80-6.

58. D’Hondt M, Yoshihara E, Dedrye L, Vindevoghel K, Nuytens F, et al. Transanal endoscopic operation for benign rectal lesions and T1 carcinoma. JSLS 2017; doi: 10.4293/JSLS.2016.00093.

59. Serra-Aracil X, Mora-Lopez L, Alcantara-Moral M, Caro-Tarrago A, Gomez-Diaz CJ, et al. Transanal endoscopic surgery in rectal cancer. World J Gastroenterol 2014;20:11538-45.

60. Serra-Aracil X, Mora-Lopez L, Alcantara-Moral M, Caro-Tarrago A, Navarro-Soto S. Transanal endoscopic microsurgery with 3-D (TEM) or high-definition 2-D transanal endoscopic operation (TEO) for rectal tumors. A prospective, randomized clinical trial. Int J Colorectal Dis 2014;29:605-10.

61. Atallah S, Martin-Perez B, Albert M, deBeche-Adams T, Nassif G, et al. Transanal minimally invasive surgery for total mesorectal excision (TAMIS-TME): results and experience with the first 20 patients undergoing curative-intent rectal cancer surgery at a single institution. Tech Coloproctol 2014;18:473-80.

62. McCarroll RH, Moore LJ. Transanal minimally invasive surgery for resection of retrorectal cyst. J Surg Case Rep 2018; doi: 10.1093/ jscr/rjy021. 
63. deBeche-Adams T, Hassan I, Haggerty S, Stefanidis D. Transanal minimally invasive surgery (TAMIS): a clinical spotlight review. Surg Endosc 2017;31:3791-800.

64. Sahnan K, Pellino G, Adegbola SO, Tozer PJ, Chandrasinghe P, et al. Development of a model of three-dimensional imaging for the preoperative planning of TaTME. Tech Coloproctol 2018;22:59-63.

65. Atallah S, Martin-Perez B, Larach S. Image-guided real-time navigation for transanal total mesorectal excision: a pilot study. Tech Coloproctol 2015;19:67-84.

66. Atallah S, Tilahun Y, Monson JR. Real-time stereotactic navigation for the laparoscopic excision of a pelvic neoplasm. Tech Coloproctol 2016;20:599-600.

67. Atallah S, Larach SW, Monson JR. Stereotactic navigation for TAMIS-TME. Minim Invasive Ther Allied Technol 2016;25:271-7.

68. Sahnan K, Adegbola SO, Tozer PJ, Gupta A, Baldwin-Cleland R, et al. Improving the understanding of perianal crohn fistula through 3D modeling. Ann Surg 2018;267:e105-7.

69. Sahnan K, Adegbola SO, Tozer PJ, Patel U, Ilangovan R, et al. Innovation in the imaging perianal fistula: a step towards personalised medicine. Therap Adv Gastroenterol 2018;11:1756284818775060.

70. Pellino G, Warusavitarne J. Medium-term adoption trends for laparoscopic, robotic and transanal total mesorectal excision (TaTME) techniques. Tech Coloproctol 2017;21:911-3. 